\title{
Sex chromosomal abnormalities associated with equine infertility: validation of a simple molecular screening tool in the Purebred Spanish Horse
}

\author{
G. Anaya* ${ }^{*}$ A. Molina*, M. Valera ${ }^{\dagger}$, M. Moreno-Millán ${ }^{\ddagger}$, P. Azor ${ }^{\dagger}$, P. Peral-García ${ }^{\S}$ and \\ S. Demyda-Peyrás ${ }^{\S}$ \\ * Laboratorio de Diagnóstico Cenético Veterinario, Departamento de Genética, Universidad de Córdoba, CN IV KM 396, Edificio \\ Gregor Mendel, Campus Rabanales, Córdoba 14071, España. `Departamento de Ciencias Agroforestales, Escuela Tecnica Superior de \\ Ingeniería Agronómica, Universidad de Sevilla, Ctra, de Utrera km 1, 41013, Sevilla, España. "Laboratorio de Citogenética Animal \\ Aplicada y Molecular, Departamento de Genética, Universidad de Córdoba, CN IV KM 396, Edificio Cregor Mendel, Campus Rabanales, \\ Córdoba, 14071, España. "Instituto de Genética Veterinaria "Ing. Fernando N. Dulout" (UNLP - CONICET LA PLATA), Facultad de \\ Ciencias Veterinarias, Universidad Nacional de La Plata, Calle 60 y 118 s/n, 1900, La Plata, Argentina.
}

\section{Summary}

\begin{abstract}
Chromosomal abnormalities in the sex chromosome pair (ECAX and ECAY) are widely associated with reproductive problems in horses. However, a large proportion of these abnormalities remains undiagnosed due to the lack of an affordable diagnostic tool that allows for avoiding karyotyping tests. Hereby, we developed an STR (single-tandem-repeat)based molecular method to determine the presence of the main sex chromosomal abnormalities in horses in a fast, cheap and reliable way. The frequency of five ECAXlinked (LEXO26, LEXOO3, TKY38, TKY270 and UCDEQ502) and two ECAY-linked (EcaYH12 and SRY) markers was characterized in 261 Purebred Spanish Horses to determine the efficiency of the methodology developed to be used as a chromosomal diagnostic tool. AII the microsatellites analyzed were highly polymorphic, with a sizeable number of alleles (polymorphic information content $>0.5$ ). Based on this variability, the methodology showed $100 \%$ sensitivity and $99.82 \%$ specificity to detect the most important sex chromosomal abnormalities reported in horses (chimerism, Turner's syndrome and sex reversal syndromes). The method was also validated with $100 \%$ efficiency in 10 individuals previously diagnosed as chromosomally aberrant. This STR screening panel is an efficient and reliable molecular-cytogenetic tool for the early detection of sex chromosomal abnormalities in equines that could be included in breeding programs to save money, effort and time of veterinary practitioners and breeders.
\end{abstract}

Keywords chimerism, diagnostic tool, equines, genetic infertility, microsatellites, molecular characterization, mosaicism, sex reversal syndrome, turner syndrome

\section{Introduction}

The Purebred Spanish horse (PRE) is the main horse breed in the Iberian Peninsula and one of the most important livestock production systems in Spain, with an active population of 68971 mares and 42308 males (SanchezGuerrero et al. 2016). PRE importance exceeds the

\section{Address for correspondence}

S. Demyda-Peyrás, IGEVET - Instituto de Genética Veterinaria UNLP CONICET LA PLATA, Facultad de Ciencias Veterinarias, Universidad Nacional de La Plata, Calle 60 y 118 s/n, La Plata 1900, Argentina. E-mail: sdemyda@igevet.gob.ar

Accepted for publication 22 December 2016 economic benefits, as it is also recognized as an icon and hallmark of the culture and traditions of Spain. Every year, near 10000 new individuals are evaluated and included in the breeding program. However, sex chromosomal abnormalities are rarely reported in these animals, despite the fact that their prevalence in Polish breeds is close to $2 \%$ (Bugno et al. 2007). The horse karyotype $(2 n=64)$ has 31 pairs of autosomal chromosomes (ECA1-ECA31) and two sex chromosomes (ECAX and ECAY). Its high complexity is evidenced by the presence of a large number of small acrocentric chromosomes (including ECAY) that could be easily mis-identified and by the fact that several metacentric chromosomes (ECA1-ECA6) could be misleadingly taken as ECAX (Bowling et al. 1997). The prevalence of sex 
chromosomal abnormalities in horses is more common than in other domestic animals; more than 95\% of them are linked to numeric alterations in the sexual pair (Lear \& McGee 2012). Historically, karyotype alterations have been diagnosed by cellular cultures and classical (direct karyotyping or banding) or molecular (fluorescence in situ hybridization, FISH) cytogenetic techniques (Lear \& Bailey 2008). However, these methods are difficult, expensive and time consuming, and the number of Iaboratories that may perform them is small. This situation, and the fact that most of the horses with sex chromosomal pathologies do not evidence any morphological abnormality or behavioral change until adulthood, has led to a higher percentage of undiagnosed cases (Lear \& Bailey 2008).

Three different syndromes are responsible for more than $90 \%$ of the aberrations observed in this species. Turner's syndrome, first described in humans in the 1950 s (Ford et al. 1959) as the absence of a sex chromosome $(2 n=63, \mathrm{X}$ in horses), is the main pathology diagnosed (Power 1987). It is usually ignored in veterinary practice because most animals bearing this disease have a normal external appearance and only a slight internal dysgenesis and irregular estrous behavior (Lear \& McGee 2012). Sex reversal syndrome is the second-most reported sex chromosomal pathology in equines and is characterized by a discordance among phenotype, sexual behavior and karyotype (Villagómez et al. 2011). Initially, this disease was reported as having two different presentations: phenotypically male animals bearing a female chromosome complement $(2 n=64, \mathrm{XX})$ and vice versa $(2 n=64, \mathrm{XY}$ mares $)$ (Kent et al. 1988). However, the characterization of the sex determining region $Y$ gene $S R Y$ in horses by Pailhoux et al. (1995) allowed for the differentiation of four possible sexreverse syndromes: male and female SRY-negative and positive individuals. Chimerism is the third most important sex chromosomal syndrome reported in horses; it has been identified in several species and widely diagnosed as Freemartinism in cattle (Jost et al. 1972). This syndrome derives from the exchange of blood tissue and hormones through placental circulation between di-zygotic twin brothers. Although this condition is of great importance in cattle, its prevalence in horses is very low because twin pregnancy is a pathological condition that is normally terminated once detected (Davies Morel et al. 2012). All of these syndromes are currently diagnosed by conventional techniques, which as was mentioned previously, are difficult, time consuming and not easily available in several countries.

Molecular markers are widely used as an effective tool for genetic identification, traceability and assessment of parentage relationships among animals (Fernández et al. 2013). This highly automated and fast methodology allows for the detection of genetic variability among individuals and can therefore be used in scientific, forensic and legal applications. A few years ago, Kakoi et al. (2005) proposed that the
STR (single-tandem-repeat)-based parentage testing could be used to detect sex chromosomal abnormalities in Thoroughbred horses. More recently, using a similar approach, we determined the presence of such abnormalities in two Andalusian horses using a simple DNA sample (Demyda-Peyras et al. 2013; Demyda-Peyrás et al. 2014). However, these methodologies did not include the detection of $S R Y$, a gene involved in gonadal differentiation during embryonic development (Berta et al. 1990). This gene has been shown to be extremely important in the differentiation of sex reversal presentations in horses (Lear \& McGee 2012), and therefore, is an interesting candidate to be included in a diagnostic tool.

To this end, we developed and characterized a cheap. reliable and fast diagnostic tool to detect the most important sex chromosomal abnormalities described in horses in a single multiplex polymerase chain (PCR) reaction. Furthermore, we comprehensively characterized the genetic variability of STR markers employed in a sample population of PRE horses, determining the sensitivity and specificity of our newly developed screening method.

\section{Material and methods}

\section{Animals}

A total of 271 animals from 90 different studs belonging to the Asociación Nacional de Criadores de Caballos de Pura Raza Española Stud Book were analyzed. Among the total PRE population of 200000 available specimens, 261 normal individuals (121 males and 140 females) were selected, minimizing their co-ancestry values, to analyze slightly related animals. Ten extra animals previously karyotyped and diagnosed as chromosomally abnormal by our laboratory (two chimeric, two with Turner's syndrome and six with sex reversal syndromes) were included as positive controls to validate the efficiency of the tool. To increase the accuracy of the validation, 20 extra normal animals (10 mares and 10 horses) included in the genomic characterization were also karyotyped. Blood samples were obtained by jugular venopunction using Tri-sodium ETDA Vacutainers $^{\mathrm{TM}}$ for DNA extraction and Na-heparin Vacutainers $^{\mathrm{TM}}$ to perform cell cultures. Hair samples (at least 50 bulbs) were also collected for DNA isolation.

\section{Molecular analyses}

DNA was obtained from blood and hair follicles using a Blood Genomic DNA Extraction Kit and a Tissue Genomic DNA Purification Kit (Canvax Biotech) respectively, according to the manufacturer's protocol. Five markers located on the ECAX (LEXOO3, UCDEQ502, TKY38, LEXO26 and TKY270) and two markers located on the ECAY (EcaYH12 and $S R Y$ ) were amplified by PCR using the primer pairs previously designed by several authors (Table 1). 
Table 1 Sequences of primers used in this study.

\begin{tabular}{|c|c|c|c|c|}
\hline Marker & Amplicon size & Primers & ECA location & References \\
\hline LEX026 (STR) & $300-318$ & $\begin{array}{l}5^{\prime}-[6-\text { FAM }] \text { TCCAGAGTGAATGGCAAATC- } 3^{\prime} \\
5^{\prime}-\text { AAGAACTAGAACCTACAACTAGG-3' }\end{array}$ & $x p$ & Coogle et al. (1996b) \\
\hline TKY38 (STR) & $105-141$ & $\begin{array}{l}5^{\prime} \text {-[6FAM]TAAGTATTCTCATAAACGGG-3' } \\
5^{\prime} \text {-GGAATAATAACAGCATCCTC-3' }\end{array}$ & Xq23 & Hirota et al. (2001) \\
\hline$T K Y 270$ (STR) & $156-172$ & $\begin{array}{l}5^{\prime} \text {-[HEX]CTGCTITAGAGAAACAAACT-3' } \\
5^{\prime} \text {-CCATGGTGAGAAAAATGAGA-3' }\end{array}$ & $x$ & Kakoi et al. (2000) \\
\hline LEX003 (STR) & $194-216$ & $\begin{array}{l}\text { 5'-[6FAM]ACATCTAACCAGTGCTGAGACT-3' } \\
5^{\prime} \text {-AAGACTAGACCTACAACTAGG-3' }\end{array}$ & $x q$ & Coogle et al. (1996a) \\
\hline UCDEQ502 (STR) & $162-176$ & $\begin{array}{l}\text { 5'-[6FAM]AGAGGGCAAAGTCAGAGCTT-3' } \\
5^{\prime} \text {-AGCACCTGATGCTTCTTGTT-3' }\end{array}$ & $x$ & Eggleston-Stott et al. (1997) \\
\hline EcaYH12 (STR) & 92 & $\begin{array}{l}5^{\prime} \text {-[6FAM]CGAACAGGTGACGAAGCATC-3' } \\
5^{\prime} \text {-GCAGACATGCACACCAACC-3' }\end{array}$ & Y & Wallner et al. (2004) \\
\hline SRY (Gene fragment) & 249 & $\begin{array}{l}5^{\prime} \text {-[HEX]TACCACCCTCCTCTTCAACG-3' } \\
5^{\prime} \text { ATCACGAGACCACACCATGA-3' }\end{array}$ & Y & Bannasch et al. (2007) \\
\hline
\end{tabular}

The type of marker is mentioned in brackets: STR: single tandem repeat (microsatellite).

Amplification was carried out using $23 \mu \mathrm{l}$ of the following mixture: 20-60 ng of genomic DNA. $1.5-7.5 \mathrm{pmol}$ of each primer pair, $0.33 \mathrm{mmol} / \mathrm{l}$ dNTPs, $2.5 \mathrm{mmol} / \mathrm{l}$ of $\mathrm{MgCl} 2$, $1.5 \mu \mathrm{I}$ of $10 \times \mathrm{PCR}$ reaction buffer and $1.5 \mathrm{U}$ of HorsePower $^{\text {TM }}$ Taq DNA polymerase (Canvax Biotech). The thermal protocol was as follows: an initial denaturation at $95^{\circ} \mathrm{C}$ for $10 \mathrm{~min}, 33 \mathrm{cycles}$ at $94^{\circ} \mathrm{C}$ for $30 \mathrm{~s}, 57^{\circ} \mathrm{C}$ for $1 \mathrm{~min}$ and $72{ }^{\circ} \mathrm{C}$ for $30 \mathrm{~s}$, followed by $72{ }^{\circ} \mathrm{C}$ for $10 \mathrm{~min}$. The amplification products were genotyped by capillary electrophoresis using an Applied Biosystems 3130 xI DNA sequencer in the Central Service for Research Support of the University of Córdoba. Allele sizes were determined after processing the raw data with the software package GENFMAPPER 4.0 using a LIZ 500 bp internal size standard (Applied Biosystems).

\section{ECAX STR- statistical analysis}

Statistical analyses were performed using GENETIX 4.0.1 (Belkhir et al. 1996-2004). Allele frequency $\left(A_{f}\right)$ as well as average $\left(X_{n}\right)$ and total number $\left(A_{n}\right)$ of alleles were determined for the entire population. Observed $\left(H_{\mathrm{ob}}\right)$ and expected $\left(H_{\mathrm{ex}}\right)$ heterozygosity were calculated only for female individuals. Allele variability (polymorphic information content, PIC) was determined for each marker in the whole population using Cervus 3.0.6. (Kalinowski et al. 2007). AF comparisons were determined using the Fisher exact test with SPSS STATISTICS 20 software (IBM). Finally, the sensitivity (proportion of positives that are correctly identified as such) and specificity (proportion of negatives that are correctly identified as such) of the diagnostic tool were determined based on allele variability in this population.

\section{Cell culture and karyotyping}

Twenty normal individuals (10 mares and 10 horses) were karyotyped to validate the molecular results.
Cytogenetic analysis was performed on metaphase chromosomes obtained from Iymphocytes cultures according to Rodero-Serrano et al. (2013). Chromosome spreads were obtained by dropping $100 \mu \mathrm{I}$ of the cell suspension onto wet slides. Giemsa-stained karyotypes were analyzed in a Cytovision platform (Leica) using the Equus caballus standardized karyotype (Richer et al. 1990) and confirmed by C-banding (Sumner 1972) in at least 100 metaphases. The type and number of abnormalities detected were recorded. DNA samples from 10 horses previously diagnosed with chromosomal abnormalities in the sexual pair were used as positive controls.

\section{Results}

\section{Genetic characterization of ECAX-linked markers}

The $A_{f}$ of ECAX markers is shown in Table 2. All of them were highly polymorphic, with the number of alleles ranging from six (TKY270) to 11 (LEXOO3). Interestingly, $A_{n}$ was higher in males for three ECAX-linked markers, with seven different alleles represented only in males (202 and 216 for LEXOO3; 302, 304 and 310 for LEXO26; and 172 and 176 for UCDEQ502). On the contrary, five different alleles (318 for LEX026; 127 and 139 for TKY 38 and 170 for UCDEQ502) were represented only in mares. Three markers (LEXO03, LEXO26 and UCDEQ502) showed a similar $A_{f}$ between sexes, whereas it was different in two of them (TKY270 and TKY38) $(P<0.05)$. Finally, $X_{n}$ per marker (8.4) also demonstrated high genetic variability in the population analyzed.

Results of $H_{\mathrm{ex}}$ and $H_{1,1}$, heterozygosity and PIC are shown in Table 3. LEXOO3 showed the highest $H_{\mathrm{ex}}(0.802)$ and $H_{1,}$, (0.761) values, whereas TKY38 (0.679) and UCDEQ502 (0.575) showed the lowest. PIC was higher than 0.50 in all ECAX-linked markers analyzed. 
Table 2 Allelic frequencies obtained in the five ECAX microsatellites used in this study.

\begin{tabular}{|c|c|c|c|}
\hline STR & Allele & $A_{f}$ females & $A_{f}$ males \\
\hline \multirow[t]{11}{*}{ LEX003 } & 194 & 0.1413 & 0.2137 \\
\hline & 198 & 0.0326 & 0.0342 \\
\hline & 200 & 0.0072 & 0.0427 \\
\hline & 202 & 0.0000 & 0.0085 \\
\hline & 204 & 0.0254 & 0.0256 \\
\hline & 206 & 0.3225 & 0.2479 \\
\hline & 208 & 0.1014 & 0.0940 \\
\hline & 210 & 0.2065 & 0.1709 \\
\hline & 212 & 0.0290 & 0.0171 \\
\hline & 214 & 0.1341 & 0.1368 \\
\hline & 216 & 0.0000 & 0.0085 \\
\hline \multirow[t]{9}{*}{ LEX026 } & 300 & 0.1522 & 0.1849 \\
\hline & 302 & 0.0000 & 0.0252 \\
\hline & 304 & 0.0000 & 0.0084 \\
\hline & 306 & 0.0833 & 0.0840 \\
\hline & 308 & 0.0543 & 0.0336 \\
\hline & 310 & 0.0000 & 0.0084 \\
\hline & 312 & 0.3152 & 0.2857 \\
\hline & 314 & 0.3913 & 0.3697 \\
\hline & 318 & 0.0036 & 0.0000 \\
\hline \multirow[t]{6}{*}{$T K Y 270$} & 156 & 0.1728 & 0.2783 \\
\hline & 164 & 0.0074 & 0.0348 \\
\hline & 166 & 0.1176 & 0.0609 \\
\hline & 168 & 0.4449 & 0.3826 \\
\hline & 170 & 0.2537 & 0.2261 \\
\hline & 172 & 0.0037 & 0.0174 \\
\hline \multirow[t]{8}{*}{ TKY 38} & 105 & 0.0906 & 0.1441 \\
\hline & 107 & 0.0725 & 0.1695 \\
\hline & 109 & 0.3949 & 0.3432 \\
\hline & 127 & 0.0036 & 0.0000 \\
\hline & 129 & 0.3877 & 0.3008 \\
\hline & 131 & 0.0217 & 0.0085 \\
\hline & 139 & 0.0072 & 0.0000 \\
\hline & 141 & 0.0217 & 0.0339 \\
\hline \multirow[t]{8}{*}{ UCDEQ502 } & 162 & 0.0531 & 0.0787 \\
\hline & 164 & 0.4735 & 0.4607 \\
\hline & 166 & 0.0398 & 0.0112 \\
\hline & 168 & 0.2434 & 0.3090 \\
\hline & 170 & 0.0177 & 0.0000 \\
\hline & 172 & 0.0000 & 0.0112 \\
\hline & 174 & 0.1726 & 0.1180 \\
\hline & 176 & 0.0000 & 0.0112 \\
\hline
\end{tabular}

STR, single tandem repeat; $A_{f}$, allele frequency.

Frequencies per allele are characterized as the fraction of total determinations segregated by sex of the individuals.

Table 3 Observed $\left(H_{\mathrm{ob}}\right)$ and expected $\left(H_{\mathrm{ex}}\right)$ heterozygosity and polymorphic information content (PIC) of the ECAX microsatellites calculated in the entire population.

\begin{tabular}{llll}
\hline STR & $H_{\mathrm{ob}}$ & $H_{\mathrm{ex}}$ & PIC \\
\hline LEX003 & 0.761 & 0.802 & 0.796 \\
LEX026 & 0.659 & 0.714 & 0.682 \\
TKY270 & 0.698 & 0.694 & 0.663 \\
TKY38 & 0.674 & 0.679 & 0.665 \\
UCDEQ502 & 0.575 & 0.682 & 0.631 \\
\hline
\end{tabular}

STR, single tandem repeat.

\section{Screening capability}

Specificity in the study sample was $99.82 \%$, estimated by the probability of finding the five STR markers in homozygosity in females with a normal karyotype (other possibilities were covered by the different result combinations). Likewise, the sensitivity of the diagnostic tool was $100 \%$, because the possibility of obtaining a diallelic result in animals with only one ECAX was null.

\section{Validation of the methodology in chromosomally abnormal individuals}

The molecular markers used in this study allowed us to determine the presence or absence of ECAX and ECAY and the number of chromosomes with a different genetic background (cell lines) through the number of alleles detected. In the same reaction, we also determined the presence of the $S R Y$ gene, which plays a crucial role in the case of sex reversal horses. Based on the combinations of the results of those seven markers, we detected most of the sex chromosomal pathologies previously associated with reproductive failures in horses $(90 \% \mathrm{CI})$.

All individuals studied using the molecular methodology proposed in this report were diagnosed correctly. The karyotypes and STR profiles in animals used as positive controls are shown in Table 4. Mares with a normal karyotype $(64, \mathrm{XX})$ showed non-amplified ECAY markers and at least one ECAX marker in heterozygosity (two alleles) (Fig. S1). Males with normal karyotype (64,XY) showed amplification for ECAY markers and only one allele peak for ECAX markers (Fig. S2). Individuals affected by the sex reversal syndrome showed karyotypes and an STR profile opposite to their phenotype. also discriminated by the presence or absence of SRY (Figs S3-S5). Animals affected by Turner's syndrome $(63, X)$ showed monoallelic results in all ECAX markers and no amplification in ECAY markers (Fig. S6). Finally, results from chimeric animals were characterized by a positive amplification for ECAY markers and a multiallelic profile (two or three alleles) for at least one of the ECAX markers (Fig. S7). Differences in DNA results from blood and hair samples indicated blood chimerism. Whereas blood DNA showed the STR chimeric profile, hair DNA showed a normal STR profile according to the sex of the individual (male or female). On the other hand, if the STR chimeric profile was detected in blood and hair DNA samples, the individual was diagnosed as a true (full body) chimeric.

\section{Discussion}

Among the main syndromes associated with unexplained infertility in horses, Turner's syndrome $(63, \mathrm{X})$ is probably the most reported one (Lear \& McGee 2012). Our results showed that this abnormality could be diagnosed with STR 
Table 4 Molecular profiles of ECAX amd ECAY STR markers and the SRY gene obtained using the methodology described in this study associated with the most important sex chromosomal abnormalities described in horses.

\begin{tabular}{|c|c|c|c|c|c|}
\hline \multirow[b]{3}{*}{ Phenotype } & \multicolumn{3}{|l|}{ Molecular genotype } & \multirow[b]{3}{*}{ Karyotype } & \multirow[b]{3}{*}{ Diagnosis } \\
\hline & \multirow[b]{2}{*}{ ECAX STR profile } & \multicolumn{2}{|c|}{ ECAY marker } & & \\
\hline & & ECAYH12 & $S R Y$ & & \\
\hline Male & One allele per marker & + & + & $64 X Y$ & Normal male \\
\hline Female & At least one marker in heterozygosis & - & - & $64, x \times$ & Normal female \\
\hline Female & One allele per marker & - & - & $63, \times 0$ & Turner's syndrome $^{1}$ \\
\hline Male & At least one marker with 2 or 3 alleles & + & + & $X X / X Y^{1}$ & Male chimerism ${ }^{2}$ \\
\hline Female & At least one marker with 2 or 3 alleles & $\mp$ & + & $X X / X Y^{1}$ & Female chimerism $^{2}$ \\
\hline Male & At least one marker in heterozygosis & - & + & $64, x \times$ & Male $S R Y$ positive DSD ${ }^{3}$ \\
\hline Male & At least one marker in heterozygosis & - & - & $64, x x$ & Male SRY negative DSD \\
\hline Female & One allele per marker & + & + & $64, X Y$ & Female $S R Y$ positive DSD \\
\hline Female & One allele per marker & + & - & $64, X Y$ & Female SRY negative DSD \\
\hline
\end{tabular}

Diagnoses were performed as the combination of the phenotype and molecular genotype of the individuals. The karyotype stated is the one associated with every different syndrome.

${ }^{1}$ Results on Turner's syndrome had a $99.82 \%$ specificity.

${ }^{2}$ The proportion of cell lines may change among individuals without affecting the results. Different results obtained from blood and hair DNA samples demonstrated blood chimerism. Similar results demonstrated true chimerism.

${ }^{3} 64, X X$ SRY + DSD has not yet been reported in horses, but it can be detected with this methodology.

markers with high reliability. Interestingly, it cannot be detected using the molecular markers routinely employed in domestic animals, such as amelogenin (Hasegawa et al. 2000) or zinc finger protein genes (Han et al. 2010), as there is no discordance between genotypic and phenotypic sex. Therefore, the number of undiagnosed cases could be higher and the prevalence underestimated. In this pathology, the diagnostic confidence obtained using our approach was higher than $98 \%$, as we saturated the ECAX with several highly variable markers that allowed for the detection of the number of chromosomes present.

Concerning the sex reversal syndrome and its presentations, only three have already been reported (Villagómez et al. 2009), with the exception of the 64,XX SRY-positive disorder in sex development (DSD). This difference with other species, such as humans (Ergun-Longmire et al. 2005 ), is probably due to the fact that $S R Y$ is located in a specific region far from the pseudo-autosomal boundary region, making the gene exchange between ECAY and ECAX unlikely (Raudsepp et al. 2010). It has been demonstrated that 64 ,XY SRY-negative DSD females is the most common presentation in sex reversal horses (Lear \& McGee 2012). Its clinical presentation is characterized by the same phenotypic presentation as that in Turner's mares, with the consequential high percentage of undiagnosed cases until adulthood (Anaya et al. 2014). Our methodology also provides a simple and reliable alternative for detecting the four possible presentations of the sex reversal syndrome (according to their sex chromosomal complements and presence or absence of $S R Y$ ) based on a simple blood sample, thus allowing for a reduction in the number of undiagnosed horses. However, this methodology cannot discriminate the cause of such abnormality, which can range from point mutations (Révay et al. 2012) to small or even large chromosomal deletions (Raudsepp et al. 2010).

Another advantage of the methodology developed here is the possibility to discriminate between true and blood chimerism. Currently, the effect of male-female blood chimerism on horse fertility is under discussion. Previous reports suggest that blood chimeras are normal (Bouters \& Vandeplassche 1972; Juras et al. 2010; Demyda-Peyras et al. 2013), even when one of the lines has been diagnosed as aberrant (Demyda-Peyrás et al. 2014). However, Bugno et al. (1999) reported idiopathic subfertility in a mare that delivered for the first time after four reproductive seasons. Considering that the twining rate in horses has been estimated at approximately $3.5 \%$ of gestations (Wolc et al. 2006 ) and that about $15 \%$ of those pregnancies produce at least one live foal (Miller \& Woods 1988), we speculate that the percentage of blood chimeric individuals among horses should be much higher than the reported cases. However, because most of the studies agree with the lack of reproductive symptoms in chimeric mares, it is highly possible that most of those animals remain undiagnosed. On the contrary, true chimerism is a different condition characterized by the fusion of two zygotes or early embryos into a single individual. It has already been reported in horses (Dunn et al. 1981) and other domestic species (Batista et al. 2000), and there is agreement that true chimerism is associated with major reproductive abnormalities in animals (Padula 2005). The use of the methodology described in the present study would allow veterinary practitioners and breeders to differentiate between these two presentations and to more appropriately manage the individuals affected, given that true chimeric individuals are sterile. On the other hand, the use of molecular 
screening could allow for the determination of the real prevalence of blood chimerism in horses.

AIl diagnostic tests are characterized by their sensitivity and specificity (Van Der Schouw et al. 1995). Screening tests, for instance, are used to quickly determine the presence of some disease in a population and therefore must be highly sensitive to avoid by all means the detection of false negatives. In molecular tests based on the combination of individual results of different STRs, sensitivity and specificity are directly related to the number of markers employed and their variability (Garvin et al. 1998). We demonstrated that the markers evaluated in our study were highly polymorphic (elevated PIC) with a high number of possible allele combinations, covering a large number of homozygous and heterozygous genotypes. With this information, the probability of a 'false female positive' result (a normal mare diagnosed as having Turner's syndrome) was 0.0017 , estimating that only one out of every 588 mares would be erroneously identified as affected by this condition (false positive). In this study, validated in 30 karyotyped animals, the accuracy of the diagnostic tool was $100 \%$. The possibility of a false negative result can be ruled out, as there is no possibility of having more than two alleles in non-chimeric animals (only one or two ECAX and therefore a maximum of one or two alleles) or of obtaining a heterozygous result in a marker in animals with only one ECAX (63,X or sex reversed animals). Although sensitivity remains fixed across horse populations, specificity can vary as a function of the STR $A_{f}$ used in the different breeds. In this sense, the PIC of several microsatellite markers previously reported in different Japanese (Tozaki et al. 2003), European (Achmann et al. 2004) and Spanish (Can̄on et al. 2000) horse breeds were similar to those obtained in our study. This fact strongly suggests that this methodology will remain highly sensitive despite the breed analyzed.

The only existing population study that determined the percentage of sex chromosomal abnormalities in horses reported a prevalence close to $2 \%$ in certain Polish autochthonous breeds (Bugno et al. 2007). Our results did not show any abnormality in the 261 newly analyzed animals, suggesting that the incidence of sex chromosomal abnormalities in PRE horses is lower. Our DNA samples were collected from animals belonging to the PRE Stud Book and were specifically selected to minimize co-ancestry among individuals, maximizing the genetic differences. With these criteria, the allele variability present in the population was determined more properly. However, all the subjects analyzed showed a normal phenotype, probably because infertile animals are usually excluded from the official registers by breeders, as they could be considered bad publicity for their herds. Yet, the lack of positive results could also be due to the reduced number of individuals screened. Therefore, a solid estimation of the real prevalence of sex chromosomal abnormalities in PRE can be obtained only with a higher number of randomly selected animals.
In conclusion, we demonstrated that the use of molecular markers could be an interesting option for detecting and screening for the most important sex chromosomal abnormalities in the horse in a fast, cheap and robust way. In addition, we estimated the sensitivity and specificity of this methodology in a given population of European horses, obtaining very reliable results (higher than $99.5 \%$ in both cases). Nevertheless, a larger number of individuals should be analyzed to obtain a more accurate idea of the prevalence of sex chromosomal abnormalities in these breeds. Overall. the use of this strategy as a screening tool integrated into official breeding programs could systematically detect, in an early and efficient way, the presence of reproductively impaired individuals, saving time and money of veterinarians and breeders.

\section{Acknowlegements}

We thank the Asociación Nacional de Criadores de Caballos de Pura Raza Española (ANCEE) for providing samples and pedigree records. This work was funded by the Veterinary Genetics Diagnostic Laboratory (LDGV) and the Molecular and Applied Animal Cytogenetic Laboratory (MERAGEM Research Group), University of Córdoba. We thank Adriana Di Maggio for language editing.

\section{References}

Achmann R., Curik I., Dovc P., Kavar T.. Bodo I., Habe F., Marti E., Solkner J. \& Brem G. (2004) Microsatellite diversity, population subdivision and gene flow in the Lipizzan horse. Animal Genetics 35. 285-92.

Anaya G., Moreno-Millán M., Bugno-Poniewierska M., Pawlina K., Membrillo A., Molina A. \& Demyda-Peyrás S. (2014) Sex reversal syndrome in the horse: Four new cases of feminization in individuals carrying a 64,XY SRY negative chromosomal complement. Animal Reproduction Science 151, 22-7.

Bannasch D., Rinaldo C., Millon L., Latson K., Spangler T., Hubberty S., Galuppo L. \& Lowenstine L. (2007) SRY negative 64.XX intersex phenotype in an American saddlebred horse. The Veterinary Journal 173, 437-9.

Batista M., González F., Cabrera F., Palomino E., Castellano E., Calero P. \& Gracia A. (2000) True hermaphroditism in a horned goat with $60 \mathrm{XX} / 60 \mathrm{XY}$ chimerism. Canadian Veterinary Journal $41,562-4$.

Belkhir K., Borsa P., Chilkhi L., Raufaste N. \& Bonhomme F. (19962004) GENETLX 4.05. logiciel sous Windows TM pour la génétique des populations. Laboratoire Génome, Populations, Interactions, CNRS UMR 5171.

Berta P., Hawkins J.R., Sinclair A.H., Taylor A., Griffiths B.L., Goodfellow P.N. \& Fellous M. (1990) Genetic evidence equating SRY and the testis-determining factor. Nature 348, 448-50.

Bouters R. \& Vandeplassche M. (1972) Twin gestation in the mare: the incidence of placental vascular anastomoses and their influence on the reproductive performance of heterosexual equine twins. Journal of Reproduction and Fertility 29. 149 . 
Bowling A.T., Breen M., Chowdhary B.P.. Hirota K., Lear T., Millon L.V., De Ponce Leon F.A., Raudsepp T. \& Stranzinger G. (1997) Report of the Third International Committee for the standardization of the domestic horse Karyotype. Davis, CA, USA. 1996. International system for cytogenetic nomenclature of the domestic horse. Chromosome Research 5, 433-43.

Bugno M., Słota E., Tischner M. \& Kozubska-Sobocińska A. (1999) A case of $64, \mathrm{XX} / 64, \mathrm{XY}$ leukocytic chimerism in a fertile mare of the Wielkopolska breed. Annals of Animal Science 26, 9-16.

Bugno M., Slota E. \& Kościelny M. (2007) Karyotype evaluation among young horse populations in Poland. Schweizer Archiv fur Tierheilkunde 149, 227-32.

Cañon J., Checa M.L., Carleos C., Vega-Pla J.L., Vallejo M. \& Dunner S. (2000) The genetic structure of Spanish Celtic horse breeds inferred from microsatellite data. Animal Genetics 31, 39-48.

Coogle L., Bailey E., Reid R. \& Russ M. (1996a) Equine dinucleotide repeat polymorphisms at loci LEX002, -003, -004, -005, -007, 008, -009, -010, -011, -013 and -014. Animal Genetics 27, 126-7.

Coogle L., Reid R. \& Bailey E. (1996b) Equine dinucleotide repeat loci from LEXO25 to LEXO33. Animal Genetics 27, 289-90.

Davies Morel M.C.G., Newcombe J.R. \& Lauber M. (2012) Manual reduction of multiple embryos in the mare: The effect on subsequent pregnancy outcome. Veterinary Journal 192, 322-5.

Demyda-Peyras S., Bugno-Poniewierska M., Pawlina K., Anaya G. \& Moreno-Millán M. (2013) The use of molecular and cytogenetic methods as a valuable tool in the detection of chromosomal abnormalities in horses: a case of sex chromosome chimerism in a Spanish Purebred colt. Cytogenetic and Genome Research 141 $277-83$.

Demyda-Peyrás S., Anaya G., Bugno-Poniewierska M., Pawlina K.. Membrillo A., Valera M. \& Moreno-Millán M. (2014) The use of a novel combination of diagnostic molecular and cytogenetic approaches in horses with sexual karyotype abnormalities: a rare case with an abnormal cellular chimerism. Theriogenology 81, $1116-22$

Dunn H.O., Smiley D., Duncan J.R. \& McEntee K. (1981) Two equine true hermaphrodites with $64, \mathrm{XX} / 64, \mathrm{XY}$ and $63, \mathrm{XO} / 64$, $\mathrm{XY}$ chimerism. The Cornell Veterinarian 71, 123-35.

Eggleston-Stott M.L., DelValle A., Bautista M., Dileanis S., Wictum E. \& Bowling A.T. (1997) Nine equine dinucleotide repeats at microsatellite loci UCDEQ136. UCDEQ405, UCDEQ412, UCDEQ425, UCDEQ437, UCDEQ467, UCDEQ487, UCDEQ502 and UCDEQ505. Animal Genetics 28, 370-1.

Ergun-Longmire B., Vinci G., Alonso L., Matthew S., Tansil S., Lin-Su K.. McElreavey K. \& New M.I. (2005) Clinical, hormonal and cytogenetic evaluation of $46, \mathrm{XX}$ males and review of the literature. Journal of Pediatric Endocrinology and Metabolism 18, 739-48.

Fernández M.E., Goszczynski D.E.. Lirón J.P.. Villegas-Castagnasso E.E., Carino M.H., Ripoli M.V., Rogberg-Muñoz A., Posik D.M., Peral-García P. \& Giovambattista G. (2013) Comparison of the effectiveness of microsatellites and SNP panels for genetic identification, traceability and assessment of parentage in an inbred Angus herd. Genetics and Molecular Biology 36, 185-91.

Ford C.E., Jones K.W., Polani P.E., De Almeida J.C. \& Briggs J.H. (1959) A sex-chromosome anomaly in a case of gonadal dysgenesis (Turner's syndrome). The Lancet 273, 711-3.

Garvin A.M., Holzgreve W. \& Hahn S. (1998) Highly accurate analysis of heterozygous loci by single cell PCR. Nucleic Acids Research 26, 3468-72.
Han S.H., Yang B.C., Ko M.S., Oh H.S. \& Lee S.S. (2010) Length difference between equine $Z F X$ and $Z F Y$ genes and its application for molecular sex determination. Journal of Assisted Reproduction and Genetics 27, 725-8.

Hasegawa T., Sato F., Ishida N., Fukushima Y. \& Mukoyama H. (2000) Sex determination by simultaneous amplification of equine SRY and amelogenin genes. Journal of Veterinary Medical Science 62, 1109-10.

Hirota K., Tozaki T., Mashima S. \& Miura N. (2001) Cytogenetic assignment and genetic characterization of the horse microsatellites. TKY4-18. TKY20, TKY22-24. TKY30-41 derived from a cosmid library. Animal Genetics 32, 160-2.

Jost A., Vigier B. \& Prepin J. (1972) Freemartins in cattle: the first steps of sexual organogenesis. Journal of Reproduction and Fertility 29. 349-79.

Juras R.. Raudsepp T.. Das P.J., Conant E. \& Cothran E.G. (2010) $\mathrm{XX} / \mathrm{XY}$ blood lymphocyte chimerism in heterosexual dizygotic twins from an American Bashkir Curly horse. case report. Journal of Equine Veterinary Science 30, 575-80.

Kakoi H., Tozaki T., Hirota K., Mashima S., Kurosawa M. \& Miura N. (2000) Ten equine microsatellite loci: TKY25, TKY26, TKY27, TKY28, TKY29, TKY267, TKY268, TKY269, TKY270 and TKY271. Animal Genetics 31, 68-9.

Kakoi H., Hirota K., Gawahara H., Kurosawa M. \& Kuwajima M. (2005) Genetic diagnosis of sex chromosome aberrations in horses based on parentage test by microsatellite DNA and analysis of Xand Y-linked markers. Equine Veterinary Journal 37, 143-7.

Kalinowski S.T., Taper M.L. \& Marshall T.C. (2007) Revising how the computer program CERvus accommodates genotyping error increases success in paternity assignment. Molecular Ecology 16 . 1099-106.

Kent M.G., Shoffner R.N., Hunter A., Elliston K.O., Schroder W., Tolley E. \& Wachtel S.S. (1988) XY sex reversal syndrome in the mare: clinical and behavioral studies, H-Y phenotype. Human Genetics 79, 321-8

Lear T.L. \& Bailey E. (2008) Equine clinical cytogenetics: the past and future. Cytogenetic and Genome Research 120, 42-9.

Lear T.L. \& McGee R.B. (2012) Disorders of sexual development in the domestic horse, Equus caballus. Sexual Development 6, 61-71.

Miller A. \& Woods G.L. (1988) Diagnosis and correction of twin pregnancy in the mare. Veterinary Clinics of North America. Equine Practice 4, 215-20.

Padula A.M. (2005) The freemartin syndrome: an update. Animal Reproduction Science 87, 93-109.

Pailhoux E., Cribiu E.P.. Parma P. \& Cotinot C. (1995) Molecular analysis of an XY mare with gonadal dysgenesis. Hereditas 122. 109-12.

Power M.M. (1987) The Chromosomes of the Horse: Karyotype Definition. Clinical Applications and Comparative Interspecies Studies. University College Dublin, Dublin.

Raudsepp T., Durkin K., Lear T.L., Das P.J., Avila F., Kachroo P. \& Chowdhary B.P. (2010) Molecular heterogeneity of XY sex reversal in horses. Animal Genetics 41(Suppl 2), 41-52.

Révay T., Villagómez D.A.F., Brewer D., Chenier T. \& King W.A. (2012) GTG mutation in the start codon of the androgen receptor gene in a family of horses with $64, \mathrm{XY}$ disorder of sex development. Sexual Development 6, 108-16.

Richer C.L., Power M.M., Klunder L.R., McFeely R.A. \& Kent M.G. (1990) Standard karyotype of the domestic horse (Equus 
caballus). Committee for Standardized Karyotype of Equus caballus. The Second International Conference for Standardization of Domestic Animal Karyotypes. INRA, Jouy-en Josas, France, 22nd-26th May 1989. Hereditas, 112, 289-93.

Rodero-Serrano E., Demyda-Peyrás S., González-Martinez A., Rodero-Franganillo A. \& Moreno-Millán M. (2013) The rob (1:29) chromosome translocation in endangered Andalusian cattle breeds. Livestock Science 158, 32-9.

Sănchez-Guerrero M.J., Molina A., Gỏmez M.D., Peña F. \& Valera M. (2016) Relationship between morphology and performance: signature of mass-selection in Pura Raza Español horse. Livestock Science 185, 148-55.

Sumner A.T. (1972) A simple technique for demonstrating centromeric heterochromatin. Experimental Cell Research 75. 304-6.

Tozaki T.. Takezaki N., Hasegawa T., Ishida N., Kurosawa M.. Tomita M., Saitou N. \& Mukoyama H. (2003) Microsatellite variation in Japanese and Asian horses and their phylogenetic relationship using a European Horse outgroup. Journal of Heredity 94, 374-80.

Van Der Schouw Y.T., Verbeek A.L.M. \& Ruijs S.H.J. (1995) Guidelines for the assessment of new diagnostic tests. Investigative Radiology 30, 334-40.

Villagómez D.A.F., Parma P., Radi O., Di Meo G., Pinton A., Iannuzzi L. \& King W.A. (2009) Classical and molecular cytogenetics of disorders of sex development in domestic animals. Cytogenetic and Genome Research 126, 110-31.

Villagómez D.A.F., Lear T.L., Chenier T., Lee S., McGee R.B., Cahill J., Foster R.A., Reyes E., St John E. \& King W.A. (2011) Equine disorders of sexual development in 17 mares including XX. SRY- negative. XY, SRY-negative and XY. SRY-positive genotypes. Sexual Development 5, 16-25.

Wallner B., Piumi F., Brem G., Müller M. \& Achmann R. (2004) Isolation of $\mathrm{Y}$ chromosome-specific microsatellites in the horse and cross-species amplification in the genus Equus. Journal of Heredity 95, 158-64.

Wolc A., Bresińska A. \& Szwaczkowski T. (2006) Genetic and permanent environmental variability of twinning in Thoroughbred horses estimated via three threshold models. Journal of Animal Breeding and Genetics 123, 186-90.

\section{Supporting information}

Additional supporting information may be found online in the supporting information tab for this article:

Figure S1 Electropherogram profile of a normal female $(64$. $\mathrm{XX)}$.

Figure S2 Electropherogram profile of a normal male.

Figure S3 Electropherogram profile of a 64,XY, SRYnegative DSD mare (sex reversal mare).

Figure S4 Electropherogram profile of a $64, \mathrm{XY}, S R Y$-positive DSD mare (sex reversal mare).

Figure S5 Electropherogram profile of a $64 \mathrm{XX}$, SRYnegative DSD male (sex reversal horse).

Figure S6 Electropherogram profile of Turner's profile $(2 n=63, \mathrm{X})$.

Figure S7 Electropherogram profiles of blood and hair DNA of an individual with blood chimerism. 